\title{
TRANSIENT STABILITY OF A ROTARY FREQUENCY CONVERTER FED RAILWAY INTERCONNECTED WITH A PARALLEL LOW FREQUENCY HIGH VOLTAGE TRANSMISSION SYSTEM
}

\author{
JOHN LAURY, MATH BOLLEN \& LARS ABRAHAMSSON \\ Electric Power Engineering, Luleå University of Technology, 93187 Skellefteå, Sweden
}

\begin{abstract}
Using low frequency High Voltage Transmission systems (HV-T) in parallel with the catenary system strengthens the railway system by reducing the total impedance of the railway grid. A consequence of the reduced impedance is that converter stations are electrically closer to each other. Inside a converter station, different types of Rotary Frequency Converters (RFCs) are used. It is not well explored how different RFCs behaves and interacts with each other during and after a large disturbance, like a short circuit. The dynamics of an RFC are modelled by using the Anderson-Fouad model of a synchronous machine. The study presented in this paper investigates interactions inside and between converter stations, with different types of RFC, for an HV-T system in parallel with a Booster Transformer catenary system. The numerical simulation results show, for instance, that the main power oscillation take place inside a converter station with mixed configuration of RFC type after fault clearance.

Keywords: railway, low frequency, $16(2 / 3) \mathrm{Hz}$, transient stability, rotary frequency converter, $R F C$, high voltage transmission, $B$ T, power oscillations, synchronous.
\end{abstract}

\section{INTRODUCTION}

Synchronous-Synchronous low frequency railway grids are used in Sweden, Norway and in the North Eastern parts of the US.

The term Synchronous-Synchronous is used when the three-phase public grid and the railway grid are connected through a three-phase synchronous motor and a single-phase synchronous generator mounted on the same mechanical shaft. This type of motor-generator set is often called a Rotary Frequency Converter (RFC) [1]. The pole ratio between motor and generator is three in Sweden and Norway and 2.4 in the US.

Studies done and published about stability of low frequency railways are few, especially for transient stability of synchronous-synchronous railway grids.

A transient stability study presented in [6] investigates how the North Eastern part of the AMTRAK railway grid behaves during a severe disturbance. Several scenarios are studied; such as faults or a loss of an RFC station. The system was found to be transiently stable for the given faults applied.

In order to strengthen the low frequency railway power system in northern Sweden, a $16 \frac{2}{3} \mathrm{~Hz}, 132 \mathrm{kV}$ High Voltage Transmission System (HV-T) was built in the 1980s. The HV$\mathrm{T}$ system is interconnected to the catenary via transformers; the total impedance of the system is reduced; and converter stations become electrically closer to each other.

In [5] a transient stability study of the aforementioned system in northern Sweden is done using the classical model of a synchronous machine. The study gives an insight on how a converter station behaves during a severe disturbance. However, the study does not consider different RFC types in the same converter station and does not show how converter stations interact with each other.

The behavior of mixed RFC types after a large disturbance in a converter station is not well explored. The authors have conducted initial studies on transient stability for mixed RFC 
types in Booster Transformer (BT) catenary system, as well as for Auto Transformer (AT) catenary systems, presented in [12] where the RFC model used is more detailed than [5].

The aim of this paper is to further explore the transient stability of SynchronousSynchronous low frequency railways. The specific contribution of this paper is the inclusion of an HV-T system in parallel with a BT catenary system. The studied system is subjected to a balanced fault at the catenary side during no-load conditions in the system.

The models of the Swedish system on which the study is based on are presented in Section 2. The different case studies are presented in Section 3. The results are presented in Section 4 and Section 5 summarizes the paper.

\section{MODELS}

\subsection{Steady state}

The active power flow from the three-phase public grid to the single-phase railway grid through a RFC, introduces a voltage phase shift [2], [3]. This voltage phase shift is composed of the motor and generator load angles and is

$$
\psi=\frac{1}{3} \arctan \left(\frac{X_{M}^{q} \cdot-P g_{M}}{U_{M}^{2}+X_{M}^{q} Q g_{M}}\right)+\arctan \left(\frac{X_{G}^{q} P g_{G}}{U_{G}^{2}+X_{G}^{q} Q g_{G}}\right) .
$$

The indices $M$ and $G$, stand for motor and generator, respectively. $X^{q}$ is the quadrature reactance and $U, P g, Q g$ are voltage, generated active and reactive power, respectively. The division by three for the motor angle is because the phase shift is expressed in $16 \frac{2}{3} \mathrm{~Hz}$ angles.

For simplicity, the leakage reactance of the step-down transformer with the motor is added to $X_{M}^{q}$ and the leakage reactance of the step-up transformer with the generator is added to $X_{G}^{q}$, with the assumption being made that the resistances are small compared to the transformer reactances.

Positive power is out from the single-phase generator, and negative from the motor. Assuming that the RFC converter is lossless, the active power of the synchronous motor and generator equals $\left(-1 \cdot P g_{M}=P g_{G}\right)$ in steady state. This implies that $P g_{M}<0$, as the motor acts as power consumer seen from the public grid.

The terminal angle of the RFC single-phase generator is referred to the angle on the three-phase grid $\theta_{50}$, to which the motor is connected. The resulting terminal angle on the single-phase generator is

$$
\theta_{16 \frac{2}{3}}=\frac{\theta_{50}}{3}-\psi
$$

With increasing active power through the RFC, the terminal angle of the RFC single-phase generator will decrease relative to the $50 \mathrm{~Hz}$ angle on the public grid.

The RFCs are often connected to a strong part of the public grid; i.e. the angle $\theta_{50}$ is assumed constant; and for simplicity of the study set to zero. It is assumed that the terminal voltage of the motor $U_{M}$ is equal to 1 p.u. and the reactive power $Q_{M}$ equal to zero. Under those assumptions made, there is no need to model an excitation system for the motor; and the field voltage of the motor is then constant.

The voltage $U_{G}$ after the single-phase transformer is controlled according to

$$
U_{G}=U_{0}-K_{i} Q g_{G i}
$$

where $U_{0}$ is the no-load voltage, $Q g_{G i}$ and $K_{i}$ are the generated reactive power and droop coefficient, respectively, for each machine $i$. The no-load voltage is set to $16.5 \mathrm{kV}$ and the 
droop coefficient is scaled according to the machine rating. In this way, reactive load sharing between RFC units in a converter station is achieved [9].

To obtain initial conditions for the systems investigated, a load flow study is done using the steady state models.

\subsection{Dynamic}

The RFC is modelled with the sixth order Anderson-Fouad synchronous machine model [7], [8]. This machine model includes the effects of damper windings. The damping coefficient $D$ is assumed zero, as damping power caused by windage and friction is small.

The machines are mounted on a common mechanical shaft and the rotor speed is therefore the same for both machines. This makes that the machine inertia constant of motor and generator can be added. The resulting swing equation of an RFC is

$$
\begin{aligned}
\dot{\delta}_{m} & =\Delta \omega_{p . u} \omega_{m 0}, \\
2 H_{p . u}^{M G} \Delta \dot{\omega}_{p . u} & =-P g_{M}-P g_{G},
\end{aligned}
$$

where $\omega_{m 0}$ is the nominal synchronous mechanical speed of the rotor, and $P g_{M} \leq 0$ as power flow is negative from the motor.

The mechanical angle is multiplied with the number of magnetic rotor pole pair for motor $\frac{p_{M}}{2}$ and generator $\frac{p_{G}}{2}$, i.e. $\delta_{M}=\frac{p_{M}}{2} \delta_{m}$ and $\delta_{G}=\frac{p_{G}}{2} \delta_{m}$, to express the rotor angle either as $50 \mathrm{~Hz}$ or as $16 \frac{2}{3} \mathrm{~Hz}$ electrical angle.

The generators of the RFCs are in Sweden often equipped with a brushless excitation system. The AC5A brushless excitation system [10] provided by MatLab is used in the model of the single-phase generator of the RFC.

\section{SYSTEM SETUP AND CASE STUDIES}

The most commonly used RFCs in the Swedish railway system are the Q38/Q39 and the Q48/Q49. The Q38/Q39 has a rated power of 4 MVA, whereas the Q48/Q49 has a rated power of 10 MVA.

The studied system consists of two Converter Stations (CSs) placed $150 \mathrm{~km}$ from each other. The system has an HV-T system in parallel, where transformers are used to connect the catenary system with the HV-T system. Transformers of 25 MVA are used between the converter stations and the HV-T system, whereas 16 MVA transformers are used for the connection between catenary system and HV-T system, see Fig. 1.

Three types of converter station configurations are investigated, see Table 1 . The configurations are investigated with a BT catenary system in parallel with the HV-T system.

An equivalent impedance of the catenary and HV-T lines based on [11] is used for the simulations, see Table 2.

Table 1: Configurations of converter stations.

\begin{tabular}{|l|l|l|l|}
\hline & Case 1 & Case 2 & Case 3 \\
\hline CS 1 & 2xQ48Q49 & 2xQ38Q39 & $\begin{array}{l}\text { 1xQ48Q49 } \\
\text { 1xQ38Q39 }\end{array}$ \\
\hline CS 2 & 2xQ48Q49 & 2xQ38Q39 & $\begin{array}{l}\text { 1xQ48Q49 } \\
\text { 1xQ38Q39. }\end{array}$ \\
\hline
\end{tabular}




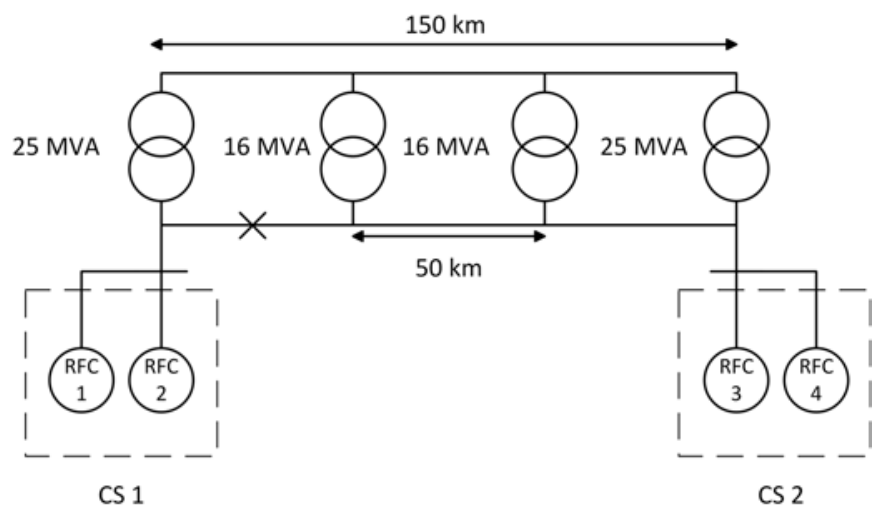

Figure 1: System studied.

Table 2: Impedances used.

\begin{tabular}{|l|l|}
\hline BT impedance & $Z_{B T}=0.2+j 0.2 \frac{\Omega}{\mathrm{km}}$ \\
\hline HV-T impedance & $Z_{H V-T}=0.102+j 0.124 \frac{\Omega}{\mathrm{km}}$ \\
\hline 25 MVA Transformer impedance & $Z t_{25 M V A}=0.065+j 0.85 \Omega$ \\
\hline 16 MVA Transformer impedance & $Z t_{16 M V A}=0.037+j 0.54 \Omega$. \\
\hline
\end{tabular}

To avoid influence of the load, the studied system has been investigated without trains. A balanced fault is assumed to occur at the catenary $25 \mathrm{~km}$ from converter station 1 . The fault is cleared after $200 \mathrm{~ms}$ by disconnection of the faulted line.

For simplicity of the study, the excitation system is assumed identical for every type of RFC. Furthermore, subtransient saliency power is neglected, which results that the subtransient direct axis reactance is equal to the subtransient quadrature reactance.

\section{RESULTS}

To find eigenvalues of an oscillation, eqn (6) presented in [4] is used.Eqn (6) is based on the time domain expression of a harmonic oscillator, and gives a simple description of an oscillation [4]. However, the expression cannot be used for complex responses, where several eigenvalues are excited [4] and other methods have to be used

$$
\alpha \pm j \omega_{o s c} \approx \frac{1}{\left(t_{2}-t_{1}\right)} \ln \left(\frac{y_{2}-y_{\infty}}{y_{1}-y_{\infty}}\right) \pm j \frac{1}{\left(t_{2}-t_{1}\right)} .
$$

The imaginary part of eqn (6) is still used to find the most dominant oscillation frequency. Two to seven (depending on how damped the oscillation is) time differences are used to obtain an average oscillation frequency.

\subsection{Case 1}

The results from Case 1 are presented Fig. 2. The rotor speed oscillations of the Q48/Q49 have a frequency of $1.96 \mathrm{~Hz}$. The single-phase active power of the individual RFC and station 


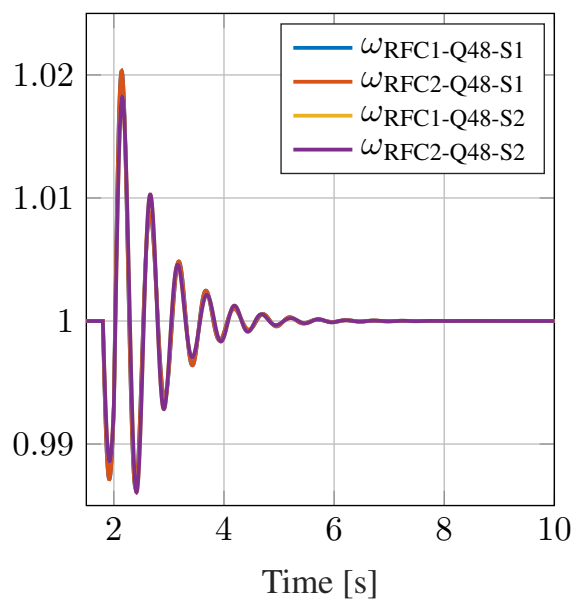

(a)

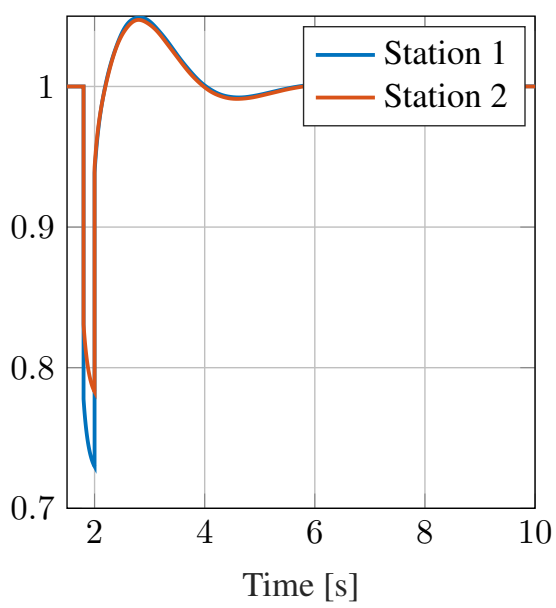

(c)

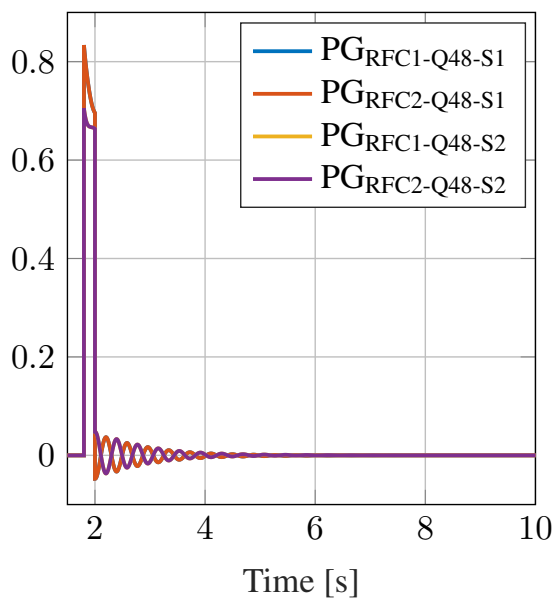

(b)

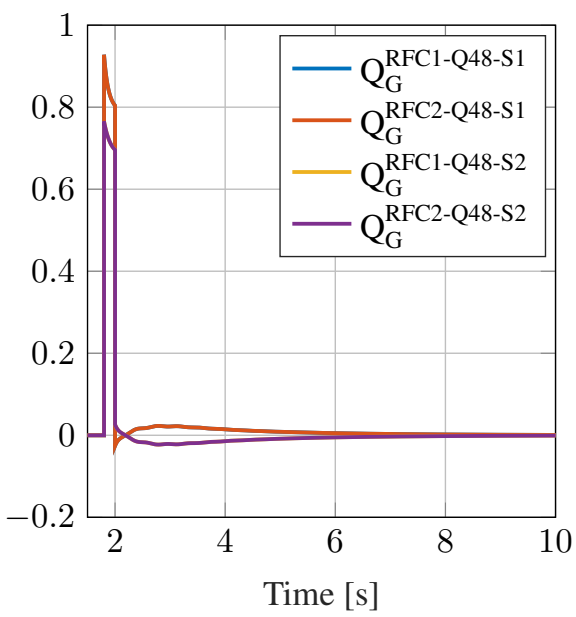

(d)

Figure 2: Case 1. Numerical results of: (a) Rotor speed [p.u.]; (b) Active power [p.u.] of each RFC; (c) Station voltage [p.u.]; and (d) Reactive power [p.u.] from each RFC.

oscillates with a frequency of $2.63 \mathrm{~Hz}$, see Fig. 2(a). The reactive power is strongly damped, and has an exponential decay with a superimposed oscillation of $2.94 \mathrm{~Hz}$.

The voltage of the stations shows strongly decaying oscillation, the oscillation frequency in the voltage is approximately $0.28 \mathrm{~Hz}$.

\subsection{Case 2}

The results for Case 2 are presented in Fig. 3. The rotor speed oscillated with a frequency of $1.68 \mathrm{~Hz}$, which is in line with results presented in [4]. 


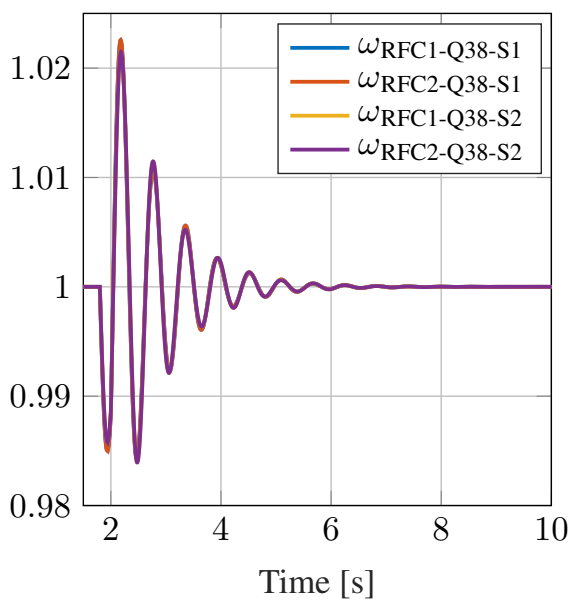

(a)

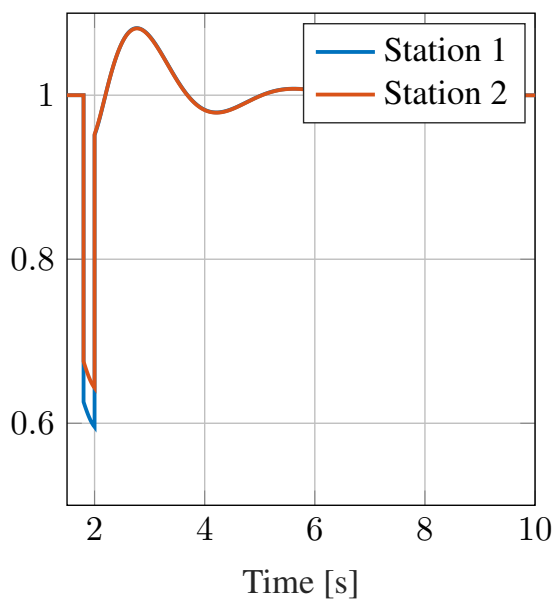

(c)

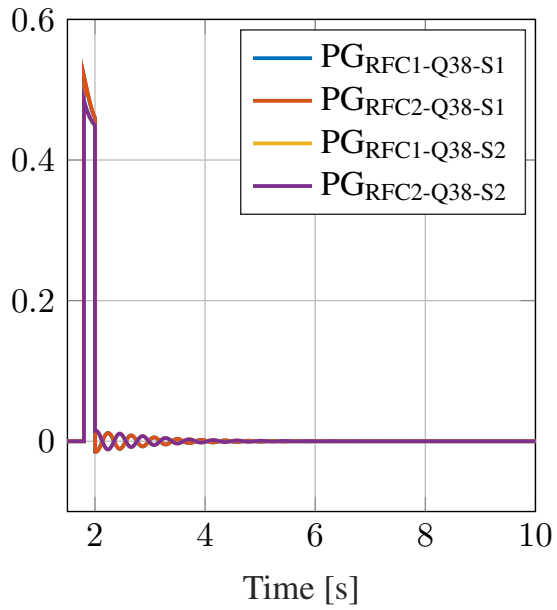

(b)

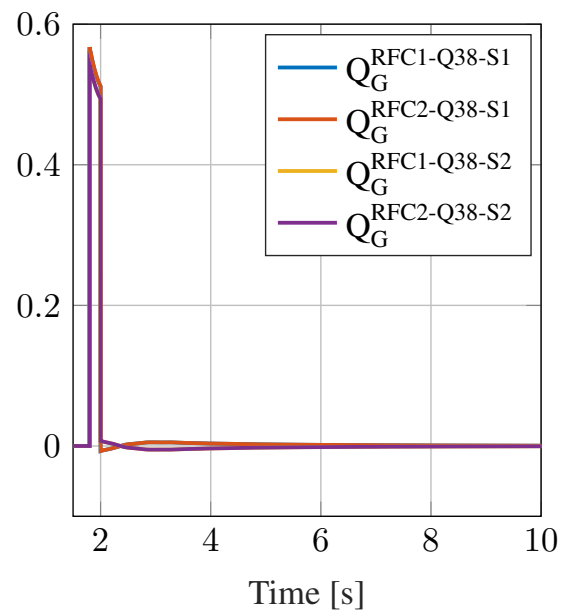

(d)

Figure 3: Case 2. Numerical results of: (a) Rotor speed, [p.u.]; (b) Active power [p.u.] of each RFC; (c) Station voltage [p.u.]; and (d) Reactive power [p.u.] from each RFC.

The single-phase active power oscillates with a frequency of $2.35 \mathrm{~Hz}$. As in Case 1, the reactive power shows a strong damping, with a superimposed oscillation of $3.11 \mathrm{~Hz}$.

The voltage of the stations show highly damped oscillations and the oscillation frequency is about $0.35 \mathrm{~Hz}$.

\subsection{Case 3}

The results for Case 3 are presented in Fig. 4. The voltage of the stations has an oscillation frequency of about $0.31 \mathrm{~Hz}$ and similar behavior as the previous cases. 


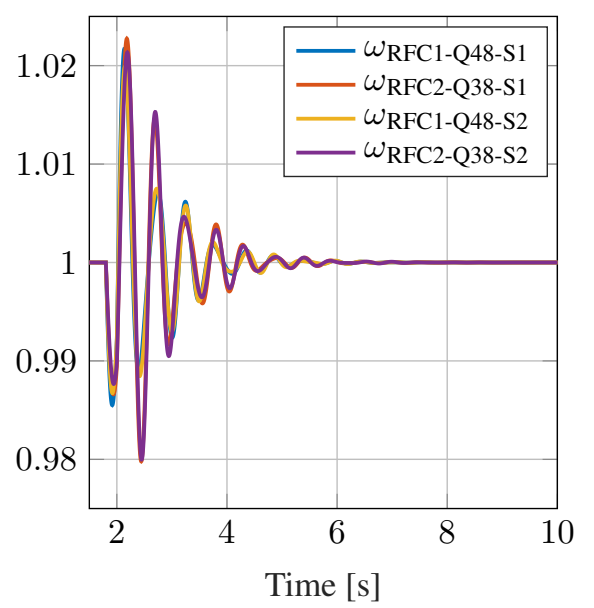

(a)

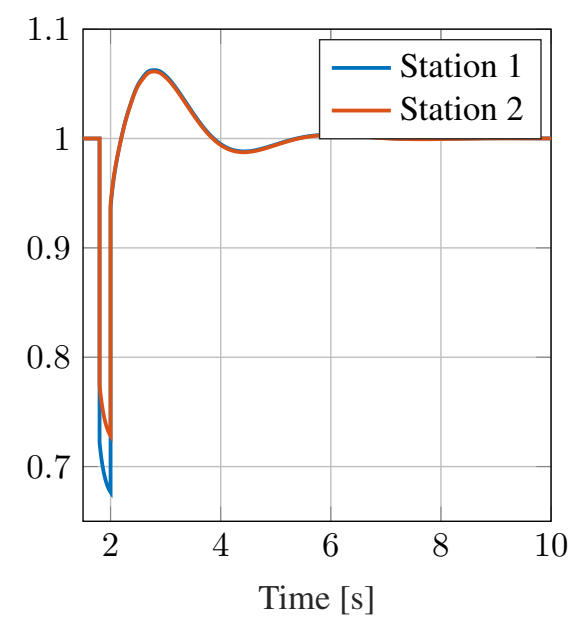

(c)

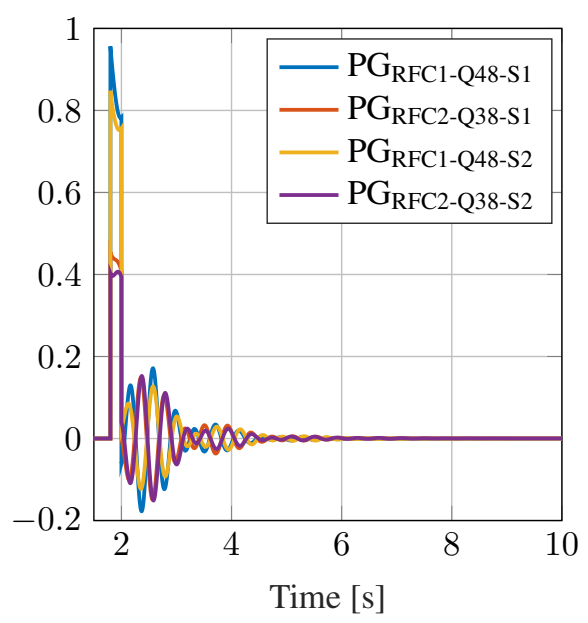

(b)

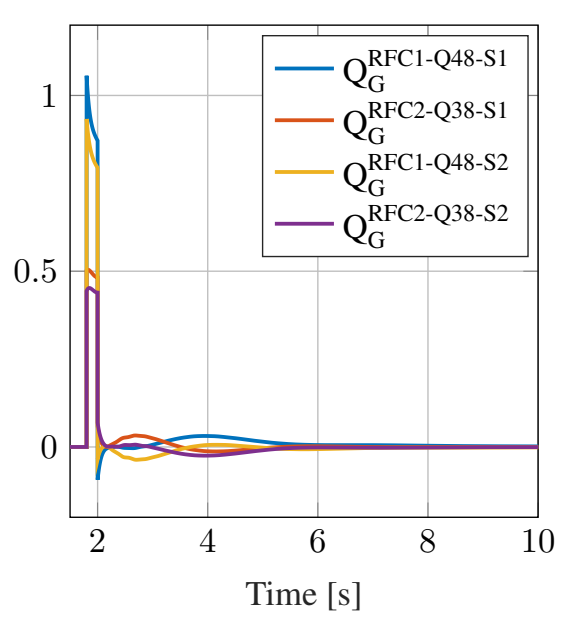

(d)

Figure 4: Case 3. Numerical results of: (a) Rotor speed, [p.u.]; (b) Active power [p.u.] of each RFC; (c) Station voltage [p.u.]; and (d) Reactive power [p.u.] from each RFC.

The average frequency of the rotor speed oscillation of all RFC is between $1.84 \mathrm{~Hz}$ and $1.87 \mathrm{~Hz}$. Thus, the average oscillation frequency of the rotor is a mix of the rotor oscillation frequency of the individual RFCs in the system.

Due to the converter station having a mixed configuration, single-phase active power oscillations occurs both inside and between converter stations. These single-phase active power oscillations are more clearly visible in Figs 5(a) and 5(b), where the main power oscillations are between the converters inside a station. It is also visible that the single-phase active power oscillations are both amplitude and phase modulated. 


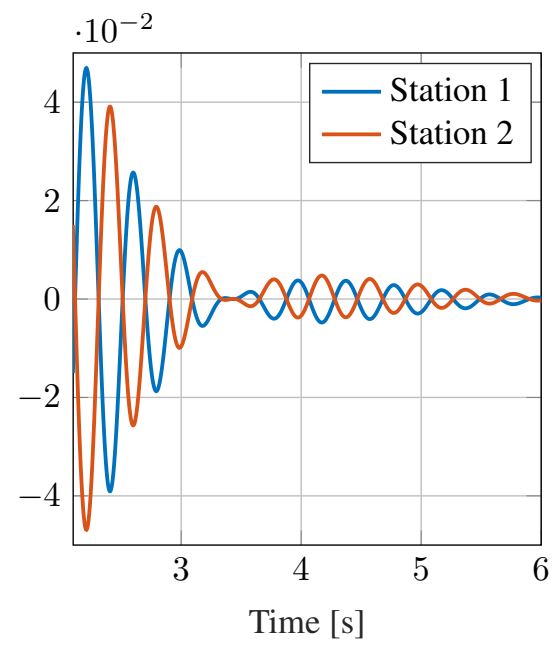

(a)

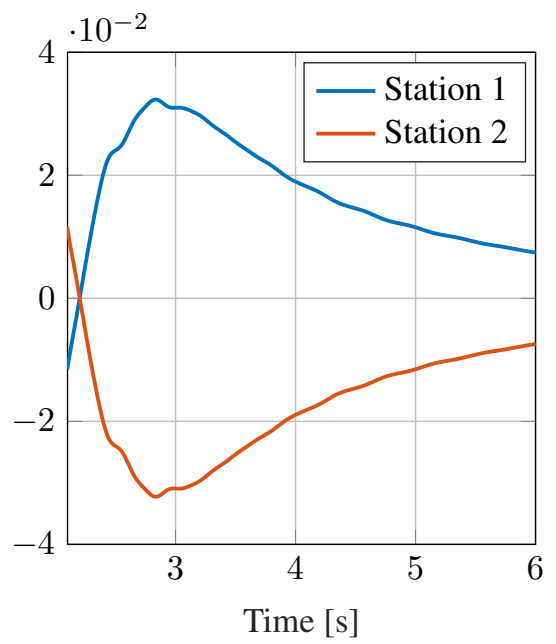

(c)

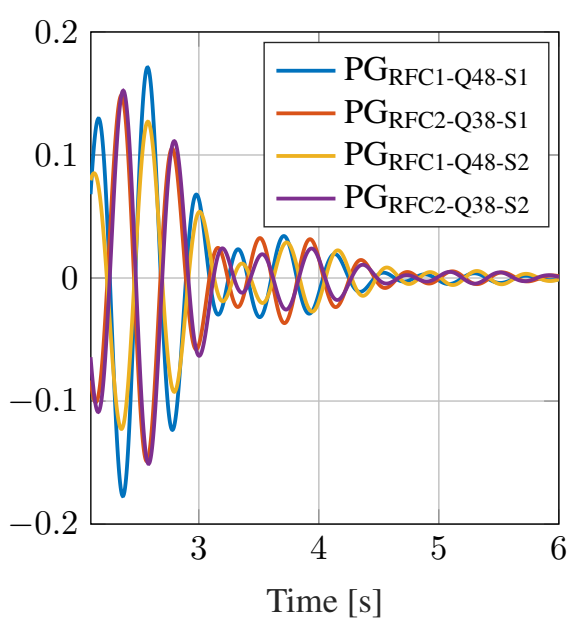

(b)

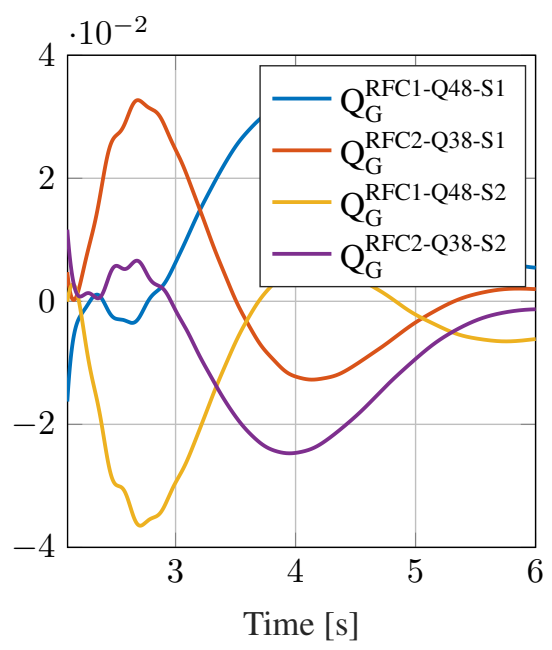

(d)

Figure 5: Case 3, zoom of: (a) Station Active Power [p.u.]; (b) Individual RFC Active Power [p.u.]; (c) Station Reactive Power [p.u.]; and (d) Individual RFC Reactive Power.

The single-phase active power oscillations from RFC inside a converter stations have a frequency of approximately 2.56 to $2.59 \mathrm{~Hz}$, whereas the single-phase active power oscillations between the stations have a frequency of approximately $2.57 \mathrm{~Hz}$. It can be seen that the single-phase active power oscillation between converter station is the average of the single-phase active power oscillations from the RFCs in a converter station.

Reactive power oscillations inside the converter stations occur with a frequency of approximately $0.29 \mathrm{~Hz}$, and the reactive powers have an imposed frequency of approximately $5.2 \mathrm{~Hz}$. The reactive power oscillations between the converter station occur at a frequency of about $0.29 \mathrm{~Hz}$. 


\section{CONCLUSIONS}

In this paper, a transient stability study of a synchronous-synchronous low frequency railway system of $16 \frac{2}{3} \mathrm{~Hz}$ has been presented. The studied railway system has a High Voltage Transmission system in parallel with the catenary system.

The rotor speed oscillations of a Q38/Q39 have an oscillation frequency of about $1.68 \mathrm{~Hz}$, which is in line with [4].

For a Q48/Q49 the corresponding oscillation frequency is about $1.96 \mathrm{~Hz}$, however field tests or obtaining the mathematical eigenvalues through linearization of the system around the operating point is needed to confirm these results.

Having a mix of these two types of RFC, results in rotor speed oscillation at a frequency about $1.84-1.87 \mathrm{~Hz}$, which is approximately the average of rotor speed oscillations of the Q38/Q39 and Q48/Q49. The single-phase active power from each RFC is amplitude modulated with a frequency of 2.56 to $2.59 \mathrm{~Hz}$ inside a converter station. Whereas the singlephase active power between the stations is amplitude modulated with a frequency of about $2.57 \mathrm{~Hz}$.

Finally, this paper has presented some characteristics of what kind of oscillations can be expected and has given more insight in the transient stability of synchronous-synchronous railway grids of $16 \frac{2}{3} \mathrm{~Hz}$. Future studies should focus on linearizing the system to more accurately obtain the oscillation frequencies, where they originate from and how they are affected by each other. It also of great importance to investigate the system in high and low traffic scenarios to see the impact of loads on the oscillations.

\section{REFERENCES}

[1] Steimel, A. Electric Traction - Motive, Power and Energy Supply, 1st ed., Oldenbourg Industrieverlag GmbH, 2008.

[2] Abrahamsson, L., Railway power supply models and methods for long-term investment analysis, Licentiate thesis, Royal Institute of Technology, Stockholm, Sweden, 2008.

[3] Olofsson, M., Optimal operation of the Swedish railway electrical system - an application of optimal power flow, $\mathrm{PhD}$ thesis, Royal Institute of Technology, Stockholm, Sweden, 1996.

[4] Danielsen, S., Electric Traction power system stability, $\mathrm{PhD}$ thesis, Norwegian University of Science and Technology, Trondheim, Norway, 2010.

[5] Olofsson, M., Investigations of transient stability in railway power supply, Master thesis, Royal Institute of Technology, Stockholm, Sweden, 1989.

[6] Eitzmann, M., Paserba, J., Undrill, J., Amicarella, C., Jones, A., Khalafalla, E. \& Liverant, W., Model Development and Stability Assessment of the Amtrak $25 \mathrm{~Hz}$ Traction System from New York to Washington DC, Joint Rail Conference, ASME/IEEE, 1997.

[7] Machowski, J., Bialek, J. \& Bumby, J., Power Systems Dynamics - Stability and Control, 2nd ed., John Wiley and Sons Ltd, 2008.

[8] Milano, F., Power System Modelling and Scripting, 1st ed., Springer, London, 2010.

[9] Laury, J., Abrahamsson, L. \& Bollen, M., Modified Voltage Control Law For Low Frequency Railway Power Systems, Joint Rail Conference, ASME, 2017.

[10] IEEE Recommended Practice for Excitation System Models for Power System Stability Studies, 2006. 
24 Computers in Railways XVI

[11] Friman, E., BK-Dokument BKE 02/28: Impedances for KTL and $132 \mathrm{kV}, 30 \mathrm{kV}$ and 15 $k V M L$, Tech. Rep., Banverket/Trafikverket, 2006.

[12] Laury, J., Abrahamsson, L. \& Bollen, M., Transient Stability of Rotary Frequency Converter Fed Low Frequency Railway Grids: The Impact of Different Grid Impedances and Different Converter Station Configurations, Joint Rail Conference, ASME, 2018. 